\title{
Aortic root translocation with atrial switch: Another surgical option for congenitally corrected transposition of the great arteries with isolated pulmonary stenosis
}

\author{
Jae Gun Kwak, MD, Chang-Ha Lee, MD, Cheul Lee, MD, and Chun Soo Park, MD, Bucheon, Korea
}

\begin{abstract}
The aortic root translocation procedure has been used for transposition of the great arteries (TGA) with a ventricular septal defect and pulmonary stenosis (PS). We report a case of aortic root translocation combined with the atrial switch operation for a patient with congenitally corrected TGA (ccTGA) with isolated PS.
\end{abstract}

\section{CLINICAL SUMMARY}

A 12-year-old boy with ccTGA (S,L,L) and isolated PS underwent anatomic repair (aortic root translocation with morphologic left ventricular outflow tract [m-LVOT] widening and a modified Senning procedure). The diagnosis was made at the age of 20 days. Catheterization data at 3 years of age showed nearly equal systolic pressure between the morphologic left ventricle $(\mathrm{m}-\mathrm{LV})$ and the morphologic right ventricle (m-RV; m-LV: $100 \mathrm{~mm} \mathrm{Hg}$ vs m-RV: 103 $\mathrm{mm} \mathrm{Hg}$ ). The patient was clinically stable. We followed him with annual echocardiographic analysis.

At 12 years of age, the patient complained of mild exercise intolerance. Catheterization and angiographic analysis revealed suprasystemic $\mathrm{m}-\mathrm{LV}$ pressure (m-LV, $140 \mathrm{~mm}$ $\mathrm{Hg}$ vs $\mathrm{m}-\mathrm{RV}, 119 \mathrm{~mm} \mathrm{Hg}$ ), severe PS, and an oxygen saturation of $94 \%$ on room air (Figure 1). At this point, anatomic repair was considered.

The operation was performed by using a standard cardiopulmonary bypass (CPB) technique. A modified Senning procedure was performed first on the fibrillating heart. After an atrial rerouting procedure, an antegrade cardioplegic solution was infused, the coronary arteries were detached from the aortic sinuses, and the aortic root was harvested. The coronary arteries showed an usual pattern in TGA (S,L,L). The main pulmonary artery was transected at just above the sinotubular junction. The incision for widening the m-LVOT was made in the middle of the conal septum (the area between the facing sinuses) and extended toward the apex to the level relieving the left ventricular outflow tract obstruction without injury of the intracardiac

\footnotetext{
From Sejong General Hospital, Sejong Heart Institution, Department of Cardiac Surgery, Bucheon, Korea.

Disclosures: None.

Received for publication June 4, 2009; revisions received Sept 2, 2009; accepted for publication Sept 22, 2009; available ahead of print Nov 30, 2009.

Address for reprints: Chang-Ha Lee, MD, Sejong General Hospital, Sejong Heart Institution, Department of Cardiac Surgery, 91-121, Sosa Bon 2 Dong, Sosa Gu, Bucheon City, Gyoeng-gi Do, Korea (E-mail: leechha@sejongh.co.kr).

J Thorac Cardiovasc Surg 2010;139:1652-3

$0022-5223 / \$ 36.00$

Copyright (c) 2010 by The American Association for Thoracic Surgery doi: $10.1016 /$ j.jtcvs.2009.09.041
}

structures, such as the atrioventricular valve. This ventriculotomy area was widened by using a bovine pericardium, with the stitches placed on the m-RV side of the septum. The harvested aortic root was turned $180^{\circ}$, translocated posteriorly, and anastomosed to the original pulmonary root site. The detached coronary arteries were reimplanted in the aortic root. Anastomosis of the transected aorta was performed after the Lecompte maneuver. After unclamping the aorta, m-RVOT reconstruction was completed with a 22-mm Carpentier-Edwards porcine-valved conduit. $\mathrm{CPB}$ weaning was uneventful, but the sternum was left open to avoid compression. CPB and aortic crossclamping times were 539 and 243 minutes, respectively. Delayed sternal closure was performed on the third postoperative day, and ventilator weaning was performed the following day. The patient was discharged after 48 days because of prolonged pleural effusion. Predischarge echocardiographic analysis showed both good ventricular function and slight left ventricular outflow tract narrowing, with a peak pressure gradient of $20 \mathrm{~mm} \mathrm{Hg}$. The postoperative electrocardiograph showed normal sinus rhythm. Six months after the operation, the patient showed good functional status (New York Heart Association functional class I).

\section{DISCUSSION}

For the treatment of ccTGA with isolated PS, several surgical options have been reported, such as pulmonary valvotomy or subvalvular widening, m-LV to PA conduit interposition, and conventional one-and-a-half ventricle repair. Concerns regarding the first 2 surgical options include progression of tricuspid regurgitation and right ventricular dysfunction, which might cause ventricular septal deviation to the $\mathrm{m}-\mathrm{LV}$ and tethering of the tricuspid valve after complete relief of PS. Backer and colleagues ${ }^{1}$ reported good outcomes of one-and-a-half ventricle repair, with partial relief of PS. In their report the ventricular septum and tricuspid valve maintain their configuration because the $\mathrm{m}-\mathrm{LV}$ is not fully decompressed by the remaining PS. However, the fate of the m-LV with partially relieved PS remains uncertain. Furthermore, this conventional one-and-a-half ventricle repair still leaves the $\mathrm{m}-\mathrm{RV}$ to be exposed to systemic circulation. The importance of the anatomic repair of ccTGA has been emphasized to prevent progressive dysfunction of the $\mathrm{m}-\mathrm{RV}$ and tricuspid regurgitation. ${ }^{2}$ This is why some surgeons have modified the original aortic translocation procedure to extend the indications. ${ }^{3}$ With our modification, 

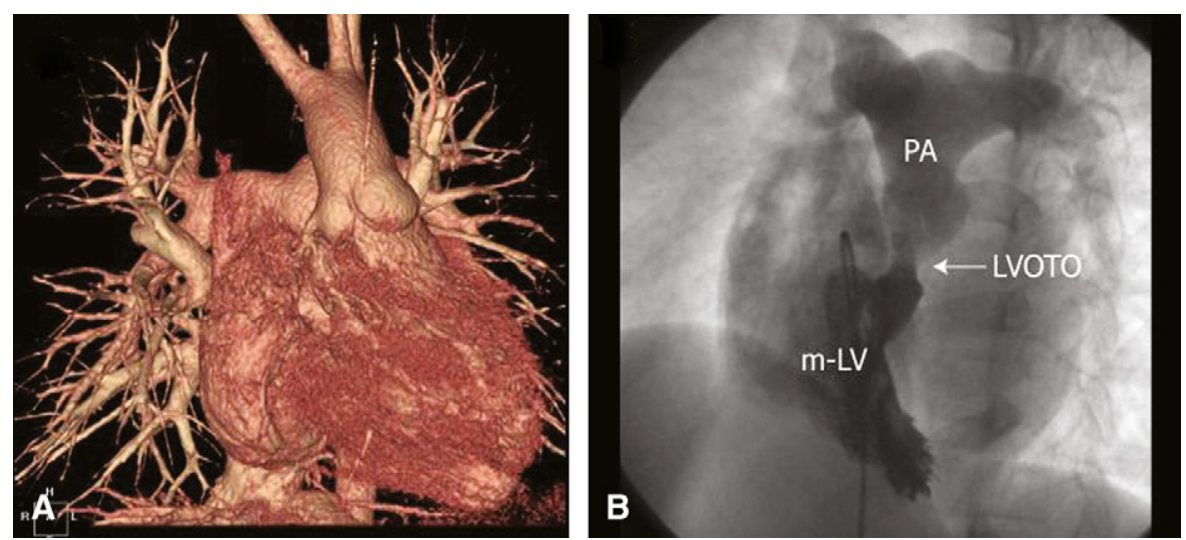

FIGURE 1. Preoperative images. A, Three-dimensional reconstructed image obtained by means of computed tomography. B, Angiograph showing severe pulmonary stenosis $(P S)$ and left ventricular outflow tract obstruction (LVOTO). $m-L V$, Morphologic left ventricle.
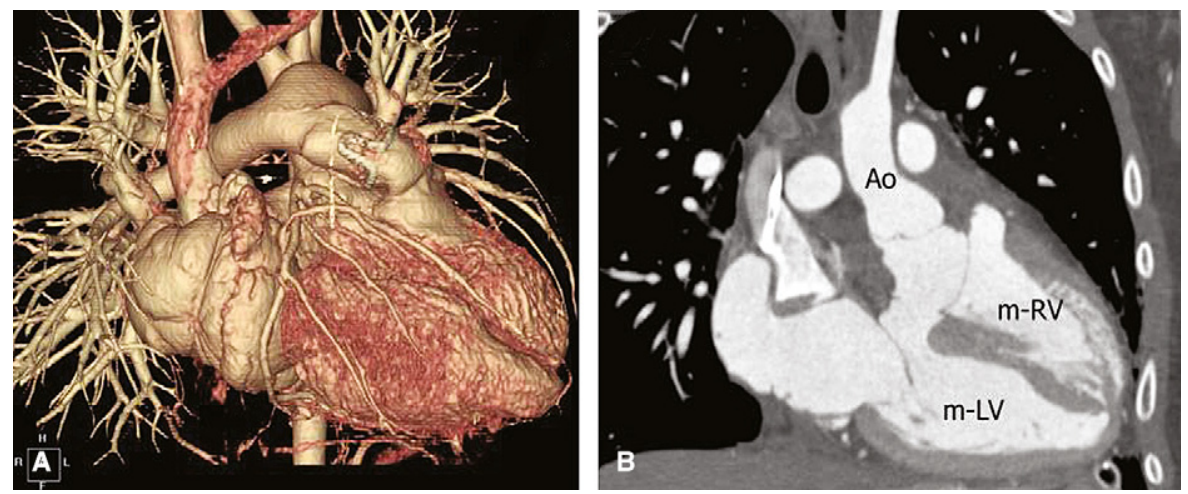

FIGURE 2. Postoperative images. A, Three-dimensional reconstructed image obtained by means of computed tomography. B, Computed tomographic image showing the newly reconstructed left ventricular outflow tract. Ao, aorta; $m-R V$, morphologic right ventricle; $m-L V$, morphologic left ventricle.

a wide systemic outflow tract (from the m-LV to the aorta) with laminar flow could be established (Figure 2).

Avoiding injury of the atrioventricular conduction pathway is also important. The incision we made in the conal septum for widening the m-LVOT was leftwardly located from the anterior part of the original pulmonary root away from the right of and anterior to the pulmonary valve where the conduction pathway might be present. ${ }^{4}$ Hosseinpour and associates ${ }^{5}$ reported many cases of normal posteroinferior conduction pathways in patients with ccTGA with PS on autopsy cases. Therefore the surgeon must consider possible atrioventricular conduction pathways during widening of the m-LVOT. The incision area in our case was distant from both possible atrioventricular conduction pathways.

Although this procedure is complicated, it can be performed safely and without significant morbidity. In addition, we anticipate better long-term results and hemodynamic status than obtained with conventional repairs in which the $\mathrm{m}-\mathrm{RV}$ is used as a systemic ventricle.

\section{References}

1. Backer CL, Stewart RD, Mavroudis C. The classical and the one-and-a-half ventricular options for surgical repair in patients with discordant atrioventricular connections. Cardiol Young. 2006;16(suppl 3):91-6.

2. Sharma R, Talwar S, Marwah A, Shah S, Maheshwari S, Suresh P, et al. Anatomic repair for congenitally corrected transposition of the great arteries. $J$ Thorac Cardiovasc Surg. 2009;137:404-12.

3. Hu SS, Li S, Wang X, Wang L, Xiong H, Li L, et al. Pulmonary and aortic root translocation in the management of transposition of the great arteries with ventricular septal defect and left ventricular outflow tract obstruction. J Thorac Cardiovasc Surg. 2007; 133:1090-2.

4. Van Praagh R, Papagiannis J, Grünenfelder J, Bartram U, Martanovic P. Pathologic anatomy of corrected transposition of the great arteries: Medical and surgical implications. Strategy for biventricular outflow tract reconstruction: Rastelli, REV, or Nikaidoh procedure? Am Heart J. 1998;135:772-85.

5. Hosseinpour A, McCarthy KP, Griselli M, Sethia B, Ho SY. Congenitally corrected transposition: size of the pulmonary trunk and septal malalignment. Ann Thorac Surg. 2004;77:2163-6. 